\title{
RESEARCH FACTORS INFLUENCING STUDENTS ACCOUNTING CAREER PATH: A GHANAIAN PERSPECTIVE
}

\author{
Wilson Elorm Pekyi ${ }^{1 *}$, Zhang Wenfang ${ }^{2}$, Takyi Kwabena Nsiah $^{3}$, Ofori Charles ${ }^{4}$, \\ Abraham Lincoln Ayisi ${ }^{5}$
}

School of Finance and Economics, Jiangsu University, No. 301 Xuefu Road, Zhenjiang City, Jiangsu

Province, China 212013

Article DOI: https://doi.org/10.36713/epra7841

DOI No: 10.36713/epra7841

\begin{abstract}
Due to increasing demands for the accounting professional and limited studies devoted to the accounting context in developing countries like Ghana. This investigates the objectives to explore the factors influencing students accounting careers paths. A closed-ended questionnaire based on 5-point Likert scale was administered to record response. Data was collected through online survey and shared via WeChat and WhatsApp among the university's students. The SmartPLS 3.0 was employed to run analysis on 337 valid responses. The research findings include the positive and significant effect of financial benefits, influence of third parties and cost and benefits on students accounting careers path. The model of the study explained 57.2\% variation. The research evidenced that among the factors financial benefits has a strongest influence on students' intentions towards accounting career path. The study also has several theoretical and practical implication for the scholars and practitioner.
\end{abstract}

KEYWORD: Financial benefits, influence of third parties, cost and benefits, accounting career path.

JEL classification code: M20, M41

\section{INTRODUCTION}

Globally, selecting a course of specialization is most crucial and future-oriented decision among students. In general, students have to choose a subject of their interest at a particular time in their academic life. Generally, academic institutes (universities, schools, colleges) offer a variety of career paths and specialization areas' such as marketing, management, entrepreneurship, finance, and accounting as traditional business discipline to their student. However, previous studies highlighted that there is constant decline in number of students to looking for accounting as their career path (Wen et al., 2018; Yusheng et al., 2020). Furthermore, the continuing decrease in the accounting students has created cautious situation for the stakeholders, and policymakers because the emerging countries are facing increasing scarcity due to global demand, most of the qualified and talented left the developing countries they resides in (Ngoc Tien, 2020).

Accordingly, (Wen et al., 2018), identified that a difficulty in attracting students is the prime factor behind the shortage of accounting professionals. In addition, students negative perception, misinformation about the workload and low salary have also been recognized to be a mean of this concern (Suryani, 2018). Moreover, (Polvillo \& Vazquez, 2018) recently noticed that students usually take decision about their career paths grounded on preconceived insights, work environment and inaccurate perceptions. While (Baxter \& Kavanagh, 2012; Wen et al., 2018) stated that those who do not opt to accounting and finance majors believe that it requires extensive mathematical/numerical skills, memorizing and it's a choice of introvert and boring people. Therefore, this study objectives to identify the factors influencing students to choose accounting career path.

Previously, there are several studies who put efforts to explore factors influencing careers choice in general. For example, familial, situational, and societal (Fenu et al., 2021), demographic variables (i.e., gender, peer group, parental pressure, parents educational background and income, media and grades) (Kazi \& Akhlaq, 2017), intrinsic motivation, extrinsic motivation, career exposure and influence of third parties $(\mathrm{Ng}$ et al., 2017). However, in the accounting context, there are limited studies and there is growing interest from the scholars and practitioner (Cornelia \& Desi, 2020; Ngoc Tien, 2020; Ria Sandra, 2020; Yusheng et al., 2020). Therefore, we have conducted this study to support the existing literature of accounting career path context. In addition, this study also provides comprehensive understanding of what factors influence Ghanaian students to pursue accounting career path. 


\section{LITERATURE REVIEW}

\subsection{Theoretical background}

(Agarwala, 2008) defined choice as selection of one object from others. Similarly, in this context, career choice is selecting one occupation over others alternative. The choice of career is influenced by several factors such as external (i.e., government regulation, culture, state of economy, and labor market) internal (i.e., personally satisfying network, interest in the job), interpersonal (i.e., effect of peers, family and friends). Accordingly (Ticoi ${ }^{\mathrm{a}}$ \& Albu, 2018), recently explored the significant effect of relational, financial, and intellectual factors on Romanian students accounting career path. (Owusu Godfred Matthew et al., 2019) examined the influence of students' intrinsic interest, self-interest, and confidence among Ghanaian students' major selection.

Previously, the theory of reasoned action (TRA) (Fishbein \& Ajzen, 1975) and theory of planned behavior (TPB) (Ajzen \& Fishbein, 1988) has been widely employed to study factors influencing career choice. The TRA postulate that an individual's behavior is primarily lead by intentions. These intentions identify determinants that could affect a desired behavior. Additionally (Ajzen, 1991) proclaimed that greater the extent of intentions greater will be likelihood of an individual predicting behavior. Furthermore, the TRA stated that attitude and subjective norms are two factors to identify the intentions. An attitude refers to "the disposition of an individual in evaluating a behavior (positive or negative)". And subjective norms defined as the pressure arise from the third party influencers such as family and friends, peers whether to perform or not to perform a desired behavior (Yuan et al., 2019). Moreover, (Ajzen \& Fishbein, 1988) extend the TRA to the TPB and postulates that the results of a particular action is not based on intentions but also on perceived behavior control grounded which refers to "one's ability to control a particular outcomes. Accordingly (Shneor \& Munim, 2019) by using the TPB concludes that financial benefits are within an individual's control. Grounded on the TRA and the TBP, we have formulated a conceptual framework which comprises of three independent variables namely financial benefits, the influence of third party, and cost-benefits and the one dependent variable namely accounting career path (see Figure 1)

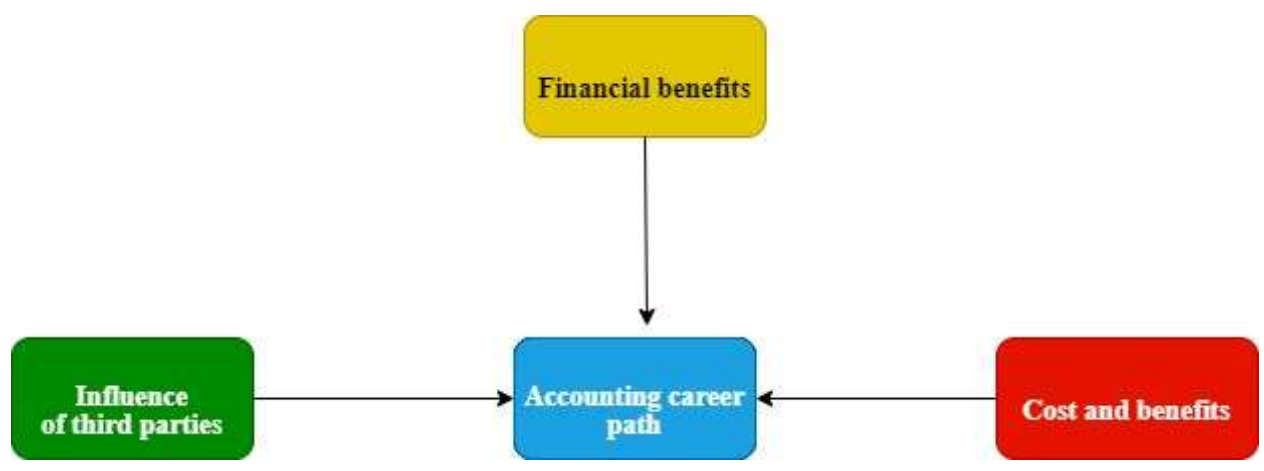

Figure 2. Conceptual framework

\subsection{Hypotheses development}

\subsubsection{Financial benefits}

Financial and socio-cultural drivers are playing a significant role in influencing students career path (Agarwala, 2008). In adequate financial benefits/rewards such as low salary, bonus, and incentives are prone to demotivation among students in choosing accounting career path among Indonesian students (Suryani, 2018). Likewise (Omar et al., 2015) also evidenced a significant role of financial terms namely salary on choosing accounting career path among undergraduate students. Not only this, financial benefits also has an effect on individual's decision to relocate and build an expatriate career (Presbitero \& Quita, 2017). (Wen et al., 2018) studied a sample of 163 undergraduate students and witnessed that compensation is the most significant influencing factor behind career path. Therefore, we hypothesize:
H1. There is a significant effect of financial benefit on choosing accounting career path.

\subsubsection{Influence of third parties}

In general, students reside in developing countries aspects hold beliefs that their accounting career choice is based on family needs, it could happen because of strong emotional bonding in these countries (Yang et al., 2002). In addition, students in African developing countries like Ghana are also facing family pressure to do jobs and take responsibilities of the families basic needs and generate future opportunities for their siblings, may impacts students accounting career path in developing countries (Yusheng et al., 2020). Previously, scholars have evidenced that accounting students are significantly influenced by the guidance of teachers, friends, relatives and family members, when they have to take decision regarding the career path (Porter \& Woolley, 2014; Tang \& Seng, 2016). However, scholar have witnessed the contradictory results concerning the effect of influence of 
third parties on students accounting career path. For example, (Hsiao \& Nova, 2016) evidenced that family has a less effect on accounting students' career path. Likewise, (Odia \& Ogiedu, 2013) witnessed that friends, teachers, parents, parents occupation and other students is less important in choosing career path. Whereas (Bekoe Rita et al., 2018) studied a sample of 457 students evidenced that course trainer, family and peers has a significant influence on accounting career path. Similarly, (Yusheng et al., 2020) also evidenced the significant effect of parents and peers on choosing accounting career. Furthermore, based on the previous calls for the validation of the results (Duffy et al., 2011; $\mathrm{Ng}$ et al., 2017; Wen et al., 2018) and to aid to existing literature on choosing accounting career path we hypothesize as

H2. There is a significant effect of influence of third parties on choosing accounting career path.

\subsubsection{Cost and benefit}

Generally, individuals across the globe perceive both benefits and cost while making decision regarding the career choice (Thing \& Jalaludin, 2018). However, a very few studies devoted to evidence the importance and influence of cost and benefits on students accounting career path (Chen et al., 2008; Felton et al., 1994; Thing \& Jalaludin, 2018). (Felton et al., 1994) explored the relationship between the intrinsic rewards, prior exposure to accounting and students of whether to select chartered accountant as a career or not. The authors evidenced that cost and benefits ratio was one of influencing factor while choosing career. (Yusheng et al., 2020) recently highlighted the importance of cost and benefits factor in choosing accounting career in global perspective. Furthermore, the authors also call for the future studies to investigate the relationship between benefits and cost and accounting career path. Therefore, this study hypothesizes as

H3. There is a significant effect of cost and benefit on choosing accounting career path.

\section{METHODOLOGY}

\subsection{Sampling and Data collection}

The present study employed a quantitative research approach and randomly selected universities students from Ghana. Due to Covid-19, an online survey containing closed-ended questionnaire was designed using Google form and disseminated through WeChat and WhatsApp application (Sikandar Ali Qalati, Dragana Ostic, et al., 2021). Besides, an online survey is considered a convenient and less costly way to collect information from the respondents (Fan, Huang, et al., 2021; Sikandar Ali Qalati, Esthela Galvan Vela, et al.,
2021). To ensure, valid response we have included two questions such as "have you been exposed to accounting in high school and do you know what accounting is." Data collection process was completed within three months from March-June 2021, to decrease the chances of bias (W. Li et al., 2020). We sent two reminder every month to remind participants to fill the 20 minutes questionnaire. The present study targeted 500 students, resulted into 337 valid responses which represents $67.4 \%$ response.

\subsection{Measures of the study}

This study adopted well developed scale from the previous studies. The financial benefits scale was assessed using five items taken from (Omar et al., 2015; Sugahara et al., 2009), recently used by (Yusheng et al., 2020). The influence of third parties measurement scale was assessed using five items adopted from the work of (Ghani et al., 2008; Hutaibat, 2012), recently used by (Ng et al., 2017). The cost and benefit factor scale assessed by using three questions taken from (Chen et al., 2008; Sugahara \& Boland, 2006). The dependent scale of the study accounting career path was assessed using four item adapted from ( $\mathrm{Ng}$ et al., 2017). The responses for all items of the scales were recorded on 5 point Likert scale, where 1 represents strongly disagree, and 5 represents strongly agree.

\subsection{Analytical tool}

The present study used both statistical package for social science (SPSS) version 25 and SmartPLS 3.0, v3.2.9. In particular, SPSS was used to test descriptive statistics of the respondents and common method bias (CMB) test. Whereas, SmartPLS 3.0 was used to tests the relationships between the constructs. In addition, this study used several techniques (i.e., PLS algorithm, bootstrapping, and blindfolding) to generate results about the proposed model and relationships. Moreover, SmartPLS 3.0 is widely used, acceptable, and suggested analytical software across the disciplines (Ahmed et al., 2020; Ali Qalati et al., 2021; Fan, Qalati, et al., 2021).

\section{RESULTS AND DISCUSSION}

\subsection{Descriptive information of respondents}

Table 1 illustrate that out of 337 , over half of them $56.4 \%$ were male and $43.6 \%$ were female students. Regarding the age most of the participants $58.8 \%$ were aged between 36 and 45 years, and $1.8 \%$ were aged under 25 years. In addition, 47.2\% (159) are master students and over one-third $37.4 \%$ were undergraduate students. Regarding the two general questions asked about the accounting career path. 290 (86.1\%) confirmed that they know about the accounting, while against second question $181(53.7 \%)$ denied that they were not exposed to accounting in high school 
Table 1. Demographic characteristics of participating students $(\mathrm{N}=337)$

\begin{tabular}{|c|c|c|c|c|c|}
\hline Respondents & & Frequency & Percentage & Mean & Std. deviation \\
\hline \multirow[t]{2}{*}{ Gender } & Male & 190 & 56.4 & 1.43 & 0.496 \\
\hline & Female & 147 & 43.6 & & \\
\hline \multirow[t]{4}{*}{ Age (years) } & $<25$ & 6 & 1.8 & 2.67 & 0.613 \\
\hline & $25-35$ & 117 & 34.7 & & \\
\hline & $36-45$ & 198 & 58.8 & & \\
\hline & $\geq 45$ & 16 & 4.8 & & \\
\hline \multirow[t]{4}{*}{ Education } & Certificate/Diploma & 6 & 1.8 & 2.72 & 0.713 \\
\hline & Undergraduate & 126 & 37.4 & & \\
\hline & Master's & 159 & 47.2 & & \\
\hline & Others & 46 & 13.6 & & \\
\hline \multirow{2}{*}{ Do you know what accounting is? } & Yes & 290 & 86.1 & & \\
\hline & No & 47 & 13.9 & & \\
\hline \multirow{2}{*}{$\begin{array}{l}\text { Have you been exposed to } \\
\text { accounting in high school? }\end{array}$} & Yes & 153 & 45.4 & & \\
\hline & No & 181 & 53.7 & & \\
\hline
\end{tabular}

This study also tests the adequacy of the sample using Kaiser-Meyer-Olkin (KMO) test. Table 2 shows that the KMO value 0.916 , which is $\geq 0.5$ acceptable threshold (Hair et al., 2019; Sikander Ali Qalati et al., 2021). Besides, the KMO test, this study also used Harman's single factor test to ensure data is free from
CMB. The Harman's single factor test value $28.6 \%$ revealed that single factor is accounted for $28.6 \%$ variation which is $<0.5$ acceptable threshold (C. Li et al., 2020). Thus, this study evidenced that there no chance of CMB.

Table 2. KMO and Bartlett's Test

\begin{tabular}{|l|c|c|}
\hline \multicolumn{2}{|c|}{ Kaiser-Meyer-Olkin Measure of Sampling Adequacy. } & 0.916 \\
\hline \multirow{3}{*}{ Bartlett's Test of Sphericity } & Approx. Chi-Square & 2577.983 \\
\cline { 2 - 3 } & $\mathrm{df}$ & 91 \\
\cline { 2 - 3 } & Sig. & .000 \\
\hline
\end{tabular}

\subsection{Analysis of the models}

The present study following (Hair et al., 2019) suggestions regarding the analysis of the model used twostep-approach assessment of measurement model and structural model.

\subsubsection{Assessment of measurement model}

The assessment of measurement model includes the tests related to reliability and validity. The individual items reliability of the study was evidenced using factors outer loading, which requires to be $\geq 0.7$ (Hair et al., 2019) (see Table 3). The Cronbach's Alpha (CA) value for all of the construct was found between 0.742 and 0.897 , however the acceptable threshold value is 0.7 (Hair et al., 2019). In addition, with regard to internal consistency (Hair et al., 2019) suggested that composite reliability (CR) must be found between 0.7 and 0.95 , the present study found $\mathrm{CR}$ values between the acceptable limit (see Table 3). present study following (Hair et al., 2019) suggestions regarding the analysis of the model used two-step-approach assessment of measurement model and structural model. Besides, regarding the convergent validity (Hair et al., 2019) recently argued that average variance extracted (AVE) value must be $\geq 0.5$, the AVE values of this research find between 0.639 and 0.708 (see Table 3). Furthermore, regarding the discriminant validity criterion of (Fornell \& Larcker, 1981), it is suggested that square root of AVE for each construct must be great than the inter-correlation of the other variables (see Table 4). Not only this we have also used variance inflation factor (VIF) test using SmartPLS 3.0 to ensure data is free from CMB. The VIF values are rage between 1.568 and 1.848 , which is quite below the acceptable threshold of 3 (Hair et al., 2019) (see Table 3). 
Table 3. Measurement model

\begin{tabular}{|c|c|c|c|c|c|c|}
\hline Construct & Item code & Loadings & CA & CR & AVE & VIF \\
\hline Financial & FB1 & 0.840 & 0.858 & 0.898 & 0.639 & 1.848 \\
\hline \multirow{4}{*}{ Benefits $(F B)$} & FB2 & 0.839 & & & & \\
\hline & FB3 & 0.834 & & & & \\
\hline & FB4 & 0.747 & & & & \\
\hline & FB5 & 0.731 & & & & \\
\hline Influence of third & IOTP1 & 0.801 & 0.864 & 0.901 & 0.646 & 2.063 \\
\hline \multirow[t]{4}{*}{ Parties (IOTP) } & IOTP2 & 0.752 & & & & \\
\hline & IOTP3 & 0.811 & & & & \\
\hline & IOTP4 & 0.803 & & & & \\
\hline & IOTP5 & 0.850 & & & & \\
\hline \multirow[t]{3}{*}{$\begin{array}{l}\text { Cost and benefits } \\
(C B)\end{array}$} & CB1 & 0.787 & 0.742 & 0.853 & 0.660 & 1.568 \\
\hline & CB2 & 0.853 & & & & \\
\hline & CB3 & 0.796 & & & & \\
\hline Accounting & ACP1 & 0.841 & 0.897 & 0.924 & 0.708 & \\
\hline \multirow[t]{4}{*}{ career path $(A C P)$} & $\mathrm{ACP} 2$ & 0.842 & & & & \\
\hline & ACP3 & 0.878 & & & & \\
\hline & $\mathrm{ACP} 4$ & 0.848 & & & & \\
\hline & ACP5 & 0.798 & & & & \\
\hline
\end{tabular}

Table 4. Discriminant validity

\begin{tabular}{|l|l|c|c|c|}
\hline & ACP & CB & FB & IOTP \\
\hline ACP & 0.842 & & & \\
\hline CB & 0.524 & 0.813 & & \\
\hline FB & 0.661 & 0.563 & 0.800 & \\
\hline IOTP & 0.667 & 0.441 & 0.587 & 0.804 \\
\hline
\end{tabular}

\subsubsection{Assessment of structural model}

Regarding the assessment of structural model coefficient of determination $\left(\mathrm{R}^{2}\right)$, cross-validatedredundancy $\left(\mathrm{Q}^{2}\right)$ and path coefficient were proposed by (Hair et al., 2019). This article used PLS bootstrapping with 1000 bootstraps and cases with the objective to describe the path coefficients, their level of significance and variance explained $\mathrm{R}^{2}$ (Henseler et al., 2009). More specifically, we have used algorithm techniques to estimate $\mathrm{R}^{2}$, bootstrapping for the hypotheses testing and blindfolding for the predictive redundancy. According to (Cohen, 1998), the value of $\mathrm{R}^{2} 0.60,0.33$ and 0.19 respectively considered as substantial, moderate and weak. The present study $\mathrm{R}^{2}$ value $57.2 \%$ stated that $57.2 \%$ changes in the accounting career path occurred due to financial benefits, influence of third parties and cost and benefit (see Table 5). All hypotheses of the study were accepted based on the criterion (t-value $>1.96$, p-value $<0.05$ ) (see Table 5 and Figure 2). Regarding the $\mathrm{Q}^{2}$ (Hair et al., 2019) suggested that values of 0.035 , 0.15 , and 0.02 , respectively, states that an exogenous construct has a large, medium, and small predictive relevance. The $\mathrm{Q}^{2}$ value 0.397 illustrated that exogenous construct has a large influence for an endogenous construct (see Table 5). In addition, (Hair et al., 2019) suggested standardized-root-mean-square-residual (SRMR) to estimate the goodness of the fit. SRMR value of this study is 0.073 which is fall below the acceptable threshold 0.08 (Hu \& Bentler, 1999) (see Table 5).

Table 5. Path coefficient and hypotheses testing

\begin{tabular}{|l|l|c|c|c|c|c|}
\hline Hypotheses & Relationships & Path coefficient & Stdv & $\boldsymbol{t}$-value & $\boldsymbol{p}$-value & Decision \\
\hline $\mathrm{H} 1$ & $\mathrm{FB} \rightarrow \mathrm{ACP}$ & 0.338 & 0.083 & $4.078^{*}$ & $0.000^{*}$ & Accepted \\
\hline $\mathrm{H} 2$ & $\mathrm{IOTP} \rightarrow \mathrm{ACP}$ & 0.399 & 0.072 & $5.565^{*}$ & $0.000^{*}$ & Accepted \\
\hline $\mathrm{H} 3$ & $\mathrm{CB} \rightarrow \mathrm{ACP}$ & 0.158 & 0.052 & $3.024^{*}$ & $0.003^{*}$ & Accepted \\
\hline $\begin{array}{l}\mathrm{R}^{2}=0.572, \text { adjusted } \mathrm{R}^{2}=0.568 ; \text { SRMR }=0.073 ; \mathrm{Q}^{2}=0.397 \\
\text { Critical value } * t \text {-value }>1.96(p \text {-value }<0.05)\end{array}$ & \multicolumn{2}{l}{} \\
\hline
\end{tabular}




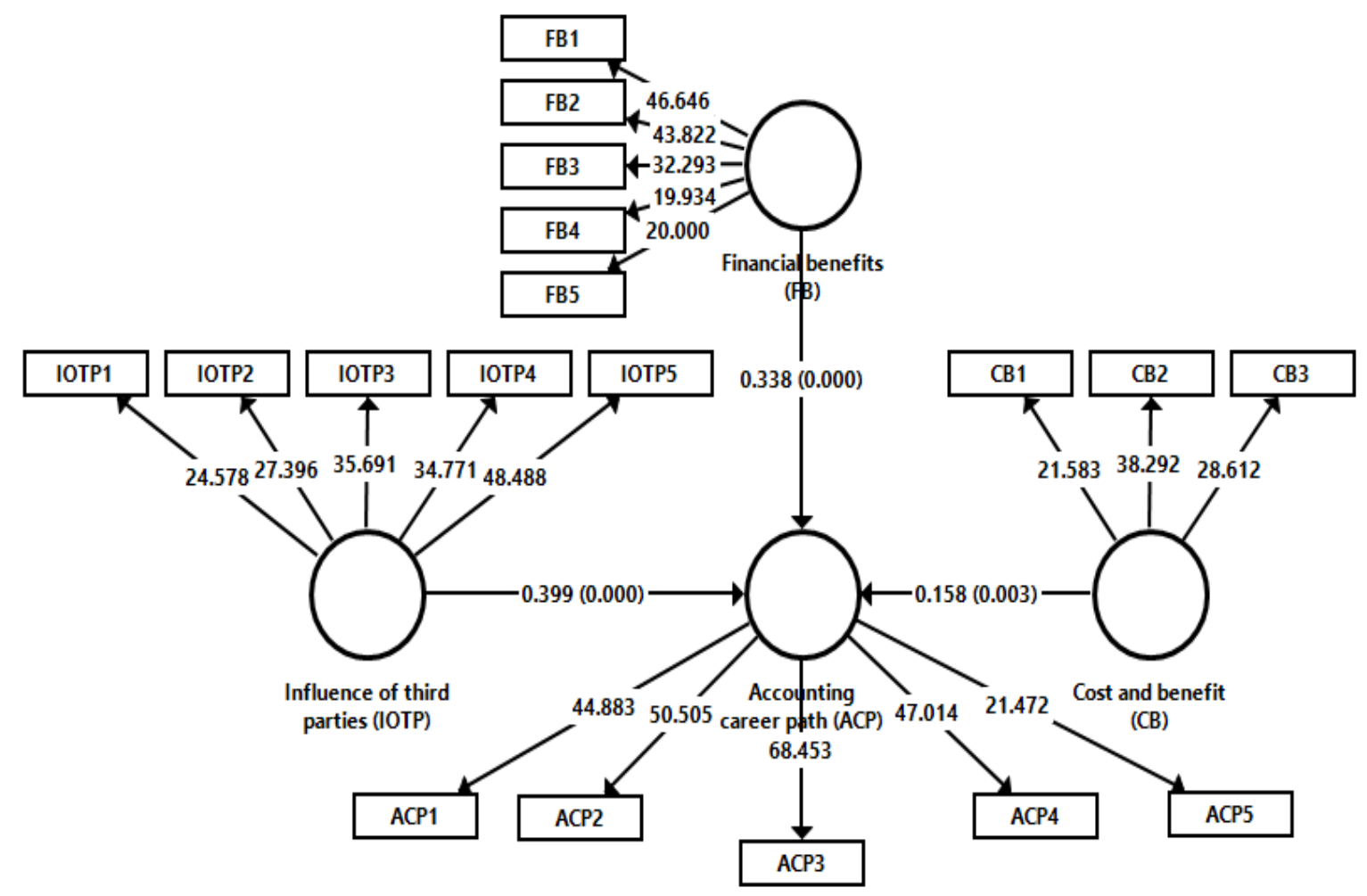

Figure 2. Structural equation modelling

The first research finding of the study reveals that financial benefits has a significant influence on accounting career path $(B=0.338$, t-value $=4.078$, $p$ value $=0.000)$ thus $H 1$ accepted. This finding of the study is in line with prior work of (Wen et al., 2018) who highlighted the importance of financial rewards and also evidence the significant impact financial rewards on accounting career choice. Second finding of the study suggested that influence of third parties has a significant effect on accounting career path $(B=0.399$, t-value $=5.567$, p-value $=0.000)$ thus $H 2$ accepted. These findings of the study are consistent with prior work of (Bekoe Rita et al., 2018; Ng et al., 2017). Third finding of the study proposed that cost and benefit has a significant effect on accounting career path $(\mathrm{B}=0.158$, t-value $=3.024$, p-value $=0.003)$ thus $H 3$ accepted. These findings of the study are supported by (Chen et al., 2005; Yusheng et al., 2020). This finding of the study infers that when students estimated that benefits of pursuing accounting as a career are greater than the cost, they will prefer, accounting.

\section{CONCLUSION}

This research used a sample of 337 students and analyzed the results using SPSS and SmartPLS 3.0 has examined the factors influencing accounting career path. The result of the present research highlighted that over half of the students did not have any exposure to accounting in high schools, thus its mandatory to for institutions and schools to create awareness among the students. The outcomes of the study suggested that financial benefits, influence of the third parties (i.e., parents, teachers, friends and peers), and cost and benefits are playing key role in choosing accounting career path. Besides, the proposed model has explained $57.2 \%$ variation.

Furthermore, this research has also offered several theoretical and practical implications. Such as this study contributed into the existing literature devoted to accounting career path. Since, Covid-19 has disturbed the whole economies across the world, and there are chances that in future developed or developing economies will face recession. In this perspective, there is going to be increase in demands for the accounting professionals. Thus, it is highly recommended for the schools, institutes and universities to increase their focus on accounting majors.

The present research also has some limitations such as convenient random sampling approach and mean to reach students can become one of the limitations, because those who are not having internet are avoided. Therefore, future studies must conduct physical surveys to record their reposes. Another limitation could be that this study conducted in one country, thus future studies suggested to be conducted at global level universities. 


\section{REFERENCE}

1. Agarwala, T. (2008). Factors influencing career choice of management students in India. Career Development International, 13(4), 362-376. doi:10.1108/13620430810880844

2. Ahmed, N., Li, C., Qalati, S. A., ur Rehman, H., Khan, A., \& Rana, F. (2020). Impact of Business Incubators on Sustainable Entrepreneurship Growth with Mediation Effect. Entrepreneurship Research Journal, 1(ahead-of-print).

3. Ajzen, I. (1991). The theory of planned behavior. Organizational behavior and human decision processes, 50(2), 179-211.

4. Ajzen, I., \& Fishbein, M. (1988). Theory of reasoned action-Theory of planned behavior. University of South Florida, 2007, 67-98.

5. Ali Qalati, S., Li, W., Ahmed, N., Ali Mirani, M., \& Khan, A. (2021). Examining the Factors Affecting SME Performance: The Mediating Role of Social Media Adoption. Sustainability, 13(1), 75. Retrieved from https://www.mdpi.com/20711050/13/1/75

6. Baxter, P., \& Kavanagh, M. (2012). Stereotypes, students' perceptions and inherent creativity: further Australian evidence. Australasian Accounting, Business and Finance Journal, 6(5), 81-100.

7. Bekoe Rita, A., Owusu Godfred Matthew, Y., Ofori Charles, G., Essel-Anderson, A., \& Welbeck Edem, E. (2018). Attitudes towards accounting and intention to major in accounting: a logistic regression analysis. Journal of Accounting in Emerging Economies, 8(4), 459-475. doi:10.1108/JAEE-01-2018-0006

8. Chen, C., Jones, K. T., \& McIntyre, D. D. (2005). A Reexamination of the Factors Important to Selection of Accounting as a Major. Accounting and the Public Interest, 5(1), 14-31. doi:10.2308/api.2005.5.1.14

9. Chen, C., Jones, K. T., \& McIntyre, D. D. (2008). Analyzing the Factors Relevant to Students' Estimations of the Benefits and Costs of Pursuing an Accounting Career. Accounting Education, 17(3), 313-326. doi:10.1080/09639280701788703

10. Cohen, J. (1998). Statistical Power Analysis for the Behavioural Sciences, xxi. In: Hillsdale, NJ: L Erlbaum associates.

11. Cornelia, A., \& Desi, A. (2020). Students' Perceptions and Expectation Gap on the Skills and Knowledge of Accounting Graduates. The Journal of Asian Finance, Economics and Business, 7(9), 649-657.

12. Duffy, R. D., Dik, B. J., \& Steger, M. F. (2011). Calling and work-related outcomes: Career commitment as a mediator. Journal of Vocational Behavior, $\quad 78(2), \quad 210-218$. doi:https://doi.org/10.1016/j.jvb.2010.09.013

13. Fan, M., Huang, Y., Qalati, S. A., Shah, S. M. M., Ostic, D., \& Pu, Z. (2021). Effects of Information Overload, Communication Overload, and Inequality on Digital Distrust: A Cyber-Violence Behavior Mechanism. Frontiers in Psychology, 12(1060). doi:10.3389/fpsyg.2021.643981

14. Fan, M., Qalati, S. A., Khan, M. A. S., Shah, S. M. M., Ramzan, M., \& Khan, R. S. (2021). Effects of entrepreneurial orientation on social media adoption and SME performance: The moderating role of innovation capabilities. PLOS ONE, 16(4), e0247320. doi:10.1371/journal.pone.0247320

15. Felton, S., Buhr, N., \& Northey, M. (1994). Factors influencing the business student's choice of a career in chartered accountancy. Issues in Accounting education, 9(1), 131.

16. Fenu, I. K., Amponsah, S., \& Nkum, W. K. (2021). Familial, Societal and Situational Factors Influencing Career Choice among Adult Learners in Ghana: Familial, Societal and Situational Factors Influencing Career Choice. Journal of Interdisciplinary Studies in Education, 10(SI), 125$145 . \quad$ Retrieved from https://ojed.org/index.php/jise/article/view/2783

17. Fishbein, M., \& Ajzen. (1975). Belief, Attitude, Intention, and Behavior: An Introduction to Theory and Research. Read-ing, MA: Addison-Wesley.

18. Fornell, C., \& Larcker, D. F. (1981). Evaluating structural equation models with unobservable variables and measurement error. Journal of marketing research, 18(1), 39-50.

19. Ghani, E. K., Said, J., Nasir, N. M., \& Jusoff, K. (2008). The 21st century accounting career from the perspective of the Malaysian university students. Asian Social Science, 4(8), 73-83.

20. Hair, J. F., Risher, J. J., Sarstedt, M., \& Ringle, C. M. (2019). When to use and how to report the results of PLS-SEM. European Business Review, 31(1), 2-24. doi:10.1108/EBR-11-2018-0203

21. Henseler, J., Ringle, C. M., \& Sinkovics, R. R. (2009). The use of partial least squares path modeling in international marketing. In New challenges to international marketing (pp. 277 319): Emerald Group Publishing Limited.

22. Hsiao, J., \& Nova, S. P. d. C. C. (2016). Generational approach to factors influencing career choice in accounting. Revista Contabilidade \& Finanças, 27(72), 393-407.

23. Hu, L. t., \& Bentler, P. M. (1999). Cutoff criteria for fit indexes in covariance structure analysis: Conventional criteria versus new alternatives. Structural equation modeling: a multidisciplinary journal, 6(1), 1-55.

24. Hutaibat, K. A. (2012). Interest in the management accounting profession: accounting students perceptions in Jordanian universities. Asian Social Science, 8(3), 303.

25. Kazi, A. S., \& Akhlaq, A. (2017). Factors Affecting Students' Career Choice. Journal of Research \& Reflections in Education (JRRE), 11(2).

26. Li, C., Ahmed, N., Qalati, S. A., Khan, A., \& Naz, S. (2020). Role of Business Incubators as a Tool for Entrepreneurship Development: The Mediating and Moderating Role of Business Start-Up and Government Regulations. Sustainability, 12(5), 1822. Retrieved from https://www.mdpi.com/20711050/12/5/1822

27. Li, W., Qalati, S. A., Khan, M. A. S., Kwabena, G. Y., Erusalkina, D., \& Anwar, F. (2020). Value Cocreation and Growth of Social Enterprises in Developing Countries: Moderating Role of Environmental Dynamics. Entrepreneurship Research Journal(20190359). doi:doi:10.1515/erj2019-0359 
28. Ng, Y.-H., Lai, S.-P., Su, Z.-P., Yap, J.-Y., Teoh, H.Q., \& Lee, H. (2017). Factors influencing accounting students' career paths. Journal of Management Development, 36(3), 319-329. doi:10.1108/JMD-11-2015-0169

29. Ngoc Tien, N. (2020). Factors Affecting Responsibility Accounting at Public Universities: Evidence from Vietnam. The Journal of Asian Finance, Economics and Business, 7(4), 275-286.

30. Odia, J., \& Ogiedu, K. (2013). Factors affecting the study of accounting in Nigerian Universities. Journal of Educational and Social Research, 3(3), 89-89.

31. Omar, M. K., Zakaria, A., Ismail, S., Sin, J. S. L., \& Selvakumar, V. (2015). Job Selection Preferences of Accounting Students in Malaysian Private Universities. Procedia Economics and Finance, 31, 91-100. doi:https://doi.org/10.1016/S22125671(15)01135-1

32. Owusu Godfred Matthew, Y., Bekoe Rita, A., Okyere Sarah, A., \& Welbeck Edem, E. (2019). What influences the course major decision of accounting and non-accounting students? Journal of International Education in Business, 12(1), 26 42. doi:10.1108/JIEB-02-2018-0004

33. Polvillo, C. F., \& Vazquez, G. P. M. (2018). Accounting and stereotypes. A comparative analysis of Mexican students' perceptions. Educade: revista de educación en contabilidad, finanzas y administración de empresas(9), 33-42.

34. Porter, J., \& Woolley, D. (2014). An examination of the factors affecting students' decision to major in accounting. International Journal of Accounting and Taxation, 2(4), 1-22.

35. Presbitero, A., \& Quita, C. (2017). Expatriate career intentions: Links to career adaptability and cultural intelligence. Journal of Vocational Behavior, 98, 118-126. doi:https://doi.org/10.1016/j.jvb.2016.11.001

36. Qalati, S. A., Ostic, D., Fan, M., Dakhan, S. A., Vela, E. G., Zufar, Z., et al. (2021). The General Public Knowledge, Attitude, and Practices Regarding COVID-19 During the Lockdown in Asian Developing Countries. International Quarterly of Community Health Education, $0272684 X 211004945$ doi:10.1177/0272684X211004945

37. Qalati, S. A., Vela, E. G., Li, W., Dakhan, S. A., Hong Thuy, T. T., \& Merani, S. H. (2021). Effects of perceived service quality, website quality, and reputation on purchase intention: The mediating and moderating roles of trust and perceived risk in online shopping. Cogent Business \& Management, $8(1)$ 1869363. doi:10.1080/23311975.2020.1869363

38. Qalati, S. A., Yuan, L. W., Khan, M. A. S., \& Anwar, F. (2021). A mediated model on the adoption of social media and SMEs' performance in developing countries. Technology in Society, 64, 101513. doi:https://doi.org/10.1016/j.techsoc.2020.101513

39. Ria Sandra, A. (2020). Accounting Knowledge as a Contributing Intention on Improving Public Accounting Profession. The Journal of Asian Finance, Economics and Business, 7(9), 801-809.
40. Shneor, R., \& Munim, Z. H. (2019). Reward crowdfunding contribution as planned behaviour: An extended framework. Journal of Business Research, 103, 56-70. doi:https://doi.org/10.1016/j.jbusres.2019.06.013

41. Sugahara, S., \& Boland, G. (2006). Perceptions of the certified public accountants by accounting and non-accounting tertiary students in Japan. Asian Review of Accounting, 14(1/2), 149-167. doi:10.1108/13217340610729518

42. Sugahara, S., Hiramatsu, K., \& Boland, G. (2009). The factors influencing accounting school students career intention to become a Certified Public Accountant in Japan. Asian Review of Accounting, 17(1), 5-22. doi:10.1108/13217340910956487

43. Suryani, A. W. (2018). The supply shortage of accounting graduates in Indonesia: The public accounting firms perspective. KnE Social Sciences, 374-387-374-387. doi:10.18502/kss.v3i3.1896

44. Tang, L. C., \& Seng, C. (2016). Factors influence students\&\#8217; choice of accounting major in Cambodian universities. Asian Review of Accounting, 24(2), 231-251. doi:10.1108/ARA-042014-0049

45. Thing, O. G., \& Jalaludin, D. (2018). Career path in accounting: what are the drivers? International Academic Journal of Accounting and Financial Management, 5(2), 161-177.

46. Ticoi ${ }^{a}, C .-F$., \& Albu, N. (2018). What factors affect the choice of accounting as a career? The case of Romania. Accounting and Management Information Systems 17(1), 137-152. doi:http://dx.doi.org/10.24818/jamis.2018.01007

47. Wen, L., Yang, H., Bu, D., Diers, L., \& Wang, $H$. (2018). Public accounting vs private accounting, career choice of accounting students in China. Journal of Accounting in Emerging Economies, 8(1), 124-140. doi:10.1108/JAEE-09-2016-0080

48. Yang, E., Sing Chee, W., Hwang, M.-h., \& Heppner, M. J. (2002). Widening Our Global View: The Development of Career Counseling Services for International Students. Journal of Career Development, 28(3), 203-213. doi:10.1177/089484530202800305

49. Yuan, L., Qalati, S., Iqbal, S., Hind, H., \& Ali, S. (2019). Impact Of Prior Work Experience On Entrepreneurial Intention And Theory Of Planned Behavior In Context Of Pakistan. Int. J. Adv. Res, 7(4), 874-887.

50. Yusheng, K., Dior, N. N. J., \& Ali, Q. S. (2020). Effects of Financial Rewards, Parents and Peers, and Benefits and Costs on Choosing Accounting Career: A Global Perspective. The Journal of Asian Finance, Economics and Business, 7(11), 157-167.

doi:10.13106/JAFEB.2020.VOL7.NO11.157 